\title{
Reseña de Pedro Calderón de la Barca, Céfalo y Pocris, introd. Enrica Cancellie- re, ed. Ignacio Arellano, New York, IDEA, 2013, 190 pp. ISBN 978-1-938795-93-0'
}

\section{Rebeca Lázaro Niso}

Universidad de La Rioja

ESPAÑA

rebeca.lazaro@unirioja.es

[Hipogrifo, (issn: 2328-1308), 5.1, 2017, pp. 503-506]

Recibido: 18-01-2017 / Aceptado: 08-02-2017

DOI: http://dx.doi.org/10.13035/H.2017.05.01.33

Esta edición publicada por IDEA/IGAS en el año 2013 hace el número 8 de la acreditada colección «Batihoja», que crece a un ritmo vertiginoso, alcanzando ya el volumen número 31. Se trata de una edición en la que dos de los más reconocidos investigadores y expertos en Calderón de la Barca, los profesores Enrica Cancelliere (Universidad de Palermo) e Ignacio Arellano (Universidad de Navarra-GRISO), Ilevan a cabo una compleja y minuciosa labor crítica.

La obra cómica de Calderón no ha sido tan estudiada como su obra seria o los autos sacramentales, de ahí que deba aplaudirse la aparición de Céfalo y Pocris, única de las comedias burlescas de Calderón de la Barca cuyo texto ha llegado hasta nosotros y probablemente una de las más representativas e ingeniosas de todo el género.

La edición crítica que tenemos en las manos ofrece al lector una comedia cargada de interés, no solo por lo que cabía esperar de la factura calderoniana, sino también por la aguda interpretación que la precede, por la erudita, precisa y detallada edición del texto y por la nutrida bibliografía que la acompaña, cualidades que la hacen disponible tanto para el público experto como para un lector menos docto en la materia.

El volumen está dividido en dos bloques bien diferenciados, conformados por el estudio introductorio, al que sigue la esmerada edición del texto. A su vez, la introducción consta de dos partes, dedicadas a la explicación de los diferentes mecanismos calderonianos de la risa y a aspectos tales como la datación de la obra

1.El texto está disponible en http://hdl.handle.net/10171/35859 [11/03/2017]. 
y el proceso de fijación textual. La primera de ellas se titula «El teatro sumergido. Prácticas del género cómico en Céfalo y Pocris, de Calderón», que corresponde a Enrica Cancelliere; la segunda, titulada «Autoría, datación, transmisión textual», de autoría de Ignacio Arellano. Por lo demás, el trabajo de edición textual corre íntegramente a cargo de la pluma del profesor Arellano.

En esta parodia grotesca se puede observar un amplio abanico de todos los mecanismos de la risa que existían en el Siglo de Oro. La profesora Cancelliere, en su detallada introducción, analiza estos y otros rasgos generales de la obra y destaca en especial esos mecanismos de la risa y divide en cuatro los pilares sobre los que asentar la acción escénica: la función primaria del decorado verbal, propio de todo texto dramático y básico en el teatro áureo; las formas retóricas, literarias y teatrales codificadas que influyen sobre el registro de la recitación; el lenguaje en sus distintas funciones «altas» y «bajas»; y el subtexto deíctico, proxémico, mímico-gestual al cual necesariamente remite el texto calderoniano por su complejidad (p. 11).

Según Cancelliere, para realizar un análisis del género cómico, paródico, burlesco, es necesario remarcar la especificidad del texto teatral con respecto a los demás géneros literarios, en el sentido de «escritura verbal» que postula y organiza la «escritura escénica» (p. 12). En definitiva, Cancelliere pretende remarcar la importancia del decorado verbal, si bien ficticio, evocado a través de una deixis en phantasma y desarrollado a lo largo de dos planos: el de la scaena ductilis y el de la poesía tanto conceptista y petrarquesca como la de tradición popular ( $\mathrm{p}$. 13). Señala además los elementos necesarios para su puesta en escena y presta especial atención al decorado de la gruta y a los diferentes usos hipotéticos de la tramoya. Además de aclarar el uso de diferentes técnicas del género cómico, enmarca la función transgresora y liberadora de esta pieza dentro de la tradición carnavalesca. Alude también a la comunicación entre el escenario y el salón de corte que mezclaba a los cómicos con el resto del público, a la cómica confusión que lleva esa dicotomía de realidad-ficción y al efecto provocado por lo oído «dentro» $\mathrm{y}$ «en el escenario» que no dejan de ser un juego entre lo que se puede oír, lo que se puede ver y, también, imaginar.

Por otro lado, analiza el sentido simbólico de los nombres de los personajes teniendo en cuenta el carácter antirrealista que adquieren y las variaciones animalescas hacia las que tiende su fisonomía, sin dejar de lado la caracterización que viene dada por el vestuario y el maquillaje. Pone de relieve la importancia de las disemias y de los chistes para buscar la risa y explica el contraste evidente entre el tono aúlico y el significado prosaico, sin dejar de lado el objetivo principal: que el público sea capaz de comprender todo aquello a lo que se alude.

Asimismo, se pone de manifiesto el contraste existente al pasarse de un lenguaje articulado de valor polisemántico a otro totalmente asemántico y expone con detalle todo tipo de registros, bien sean altos (real, cortesano, eclesiástico-litúrgico, caballeresco, humanístico, poético, dramático teatral...), bien bajos (erótico, obsceno, escatológico, culinario, gastronómico, de las germanías y del refranero), siem- 
pre teniendo en cuenta la imposibilidad de distinguir en qué momento se pasa de un registro alto a uno bajo ya que, como señala Arellano:

Destaca de manera especial en el trazado paródico de Céfalo y Pocris la acumulación de referencias textuales que la convierten en una comedia centón, [...] por un lado, el Romancero y Cancionero tradicional, sin dejar aparte las canciones y los romances cultos debidos a poetas como Lope o Góngora, y por otro el repertorio paremiológico, explotado en la manipulación jocosa de refranes y discurso lexicalizado, que se aplica literalmente, se modifica o se invierte en una galería inacabable de ingeniosidades y chistes grotescos².

Finalmente, en los planos proxémico y kinésico, Cancelliere subraya la importancia de que los actores, además de poseer una buena habilidad mímica y gestual, fueran buenos acróbatas para provocar aún más la risa del espectador en ciertas escenas. El vestuario, la actitud y la postura son fundamentales en esta obra. En definitiva, puede decirse que Cancelliere ha realizado un trabajo encomiable analizando exhaustiva y rigurosamente cada uno de los mecanismos de la risa de esta comedia. Todo ello expresado con acierto y concisión.

La segunda parte de la introducción, como hemos dicho, corre a cargo del profesor Arellano. El crítico advierte de la posible existencia de al menos otras dos posibles comedias escritas por Calderón y pertenecientes a este género (p. 31): La Celestina y Don Quijote de la Mancha (o quizá Los disparates de don Quijote), cuyos textos, sin embargo, no se han conservado. Pero de lo que sí tenemos constancia es de que Céfalo y Pocris, a pesar de que su autoría haya sido puesta en tela de juicio ${ }^{3}$, fue escrita por Calderón y se puso en escena con ocasión de las fiestas de Carnestolendas.

En cuanto a la fijación del texto, el profesor Arellano dedica un capítulo en la introducción titulado «Autoría, datación, transmisión textual» en el que hace un repaso exhaustivo y detallado que recoge las opiniones de los distintos editores e investigadores de la comedia. Sorprendentemente, Arellano recurre a un dato hasta ahora no tenido en cuenta por ellos: la presencia de la actriz María López en la comedia, con los papeles de dos personajes (compatibles) Aura y Lesbia (vv. 415, 2016). En una nota del mss. 15.197 de la Biblioteca Nacional de España, aparece que el entremés El sacristán mujer fue escrito para María López, que hace el papel de Aura en la comedia burlesca de Céfalo y Pocris. Si se tiene en cuenta que dicho entremés se suele fechar entre 1644 y 1650 y que la actriz María López murió en 1651, queda claro que la fecha de Céfalo y Pocris debe ser previa, desterrando así las hipótesis de los anteriores editores y estudiosos, que la fechaban en torno a 1660.

2. Ver Arellano, Ignacio, «Los disparates de Calderón», Anuario Calderoniano, 3, Otro Calderón. Homenaje a Maria Teresa Cattaneo, coord. Alessandro Cassol y Juan Manuel Escudero, Madrid/Frankfurt am Main, Iberoamericana/Vervuert, 2010, p. 57. (También citado en la Introducción de Cancelliere, p. 24).

3. Ver Valbuena Briones, Ángel, Perspectiva crítica de los dramas de Calderón, Madrid, Rialp, 1965, p. 325. 
Para la elaboración de la presente edición Ignacio Arellano se ha basado en la editio princeps de la Novena Parte de Vera Tassis publicada en 1691, ya que el resto de testimonios proceden en última instancia de este modelo. En general, la comedia de Vera Tassis «ofrece un texto bastante cuidado, sin grandes lagunas, según se infiere de la regularidad métrica» (p. 40). El editor subsana todas las erratas de la editio princeps, desestimando con acertado criterio la sugerencia de Roncero para el v. 1495, que sustituiría «Poul» por «Paular», ya que se rompería la secuencia métrica del romance $(u-u){ }^{4}$ Arellano ha mantenido el enigmático nombre de «Poul» y aclara en la nota a pie correspondiente que se trata de una «abreviación jocosa de 'Paular'».

Tenemos a nuestra disposición, pues, una edición crítica muy sólida desde el punto de vista filológico. El profesor Arellano ha dilucidado con fina perspicacia crítica y erudita todas las incógnitas que presenta el texto, corrigiendo y mejorando la edición previa publicada en Comedias burlescas del Siglo de Oro.

Alguna errata de tono menor, siempre inevitable por aquello de que el que inventó la imprenta inventó también la errata de imprenta, como la que se produce en la introducción (p. 17) donde el verso 1164 se lee «¿Hasla despeñada ya?», que en la edición del texto aparece en su mejor forma «¿Hasla despeñado ya?»; o la referencia en nota al verso 1495, que aparece como 1596 (p. 135), para nada desdicen de una edición filológicamente impecable.

El texto va acompañado por un nutrido número de notas a pie que se dedican a explicar o aclarar tanto las peculiaridades de carácter lingüístico como los rasgos de carácter literario, siempre de forma rigurosa y bien documentada, como propias de un crítico y editor que tiene exacto criterio para distinguir lo que constituye la nota necesaria o imprescindible de la erudición simplemente mostrenca. Un siempre utilísimo índice de voces anotadas completa el volumen, facilitando la consulta del lector.

En conclusión, se puede decir que la edición de Céfalo y Pocris que aquí reseñamos es una clara muestra de la sólida investigación que sustenta la edición de la comedia y también de una labor impecable de edición crítica, que con toda seguridad satisfará tanto a los estudiosos de Calderón como al lector aficionado al teatro del Siglo de Oro. 